\title{
BRAIN DAMAGE IN CHILDREN AFTER DEEP HYPOTHERMIA FOR OPEN-HEART SURGERY
}

\author{
BY \\ VIKING OLOV BJÖRK AND GÖSTA HULTQUIST \\ From the Thoracic Surgical Clinic and the Pathological Department, the University, Upsala, \\ Sweden
}

(RECEIVED FOR PUBLICATION JULy 4, 1960)

We have encountered brain damage in a number of children after the clinical use of deep hypothermia for open-heart surgery, and we therefore consider a warning should be given against its use by extracorporeal cooling in its present form, especially for children. Our findings have precluded the continued use of deep hypothermia for children in our clinic.

\section{MATERIAL}

The material is divided into five groups according to the different surgical techniques used for extracorporeal circulation (Table I).
GrouP 1.-Deep hypothermia was obtained by extracorporeal cooling after the method of Drew and Anderson (1959). The blood was drained from the left atrium to a reservoir and pumped through a heat exchanger back to the femoral artery. When the heart fibrillated, usually between $16^{\circ}$ and $30^{\circ} \mathrm{C}$. oesophageal temperature, blood was drained from the right atrium to a reservoir and then pumped through a catheter in the pulmonary artery via the right ventricle, oxygenated in the patient's lungs and returned to the reservoir draining the left atrium. When an oesophageal temperature of between 5.8 and $14.7^{\circ} \mathrm{C}$. had been reached, the circulation was stopped and the operation done in a bloodless flaccid heart. Rewarming

TABLE I

PATIENTS DYING AFTER EXTRACORPOREAL CIRCULATION WITH AND WITHOUT DEEP HYPOTHERMIA

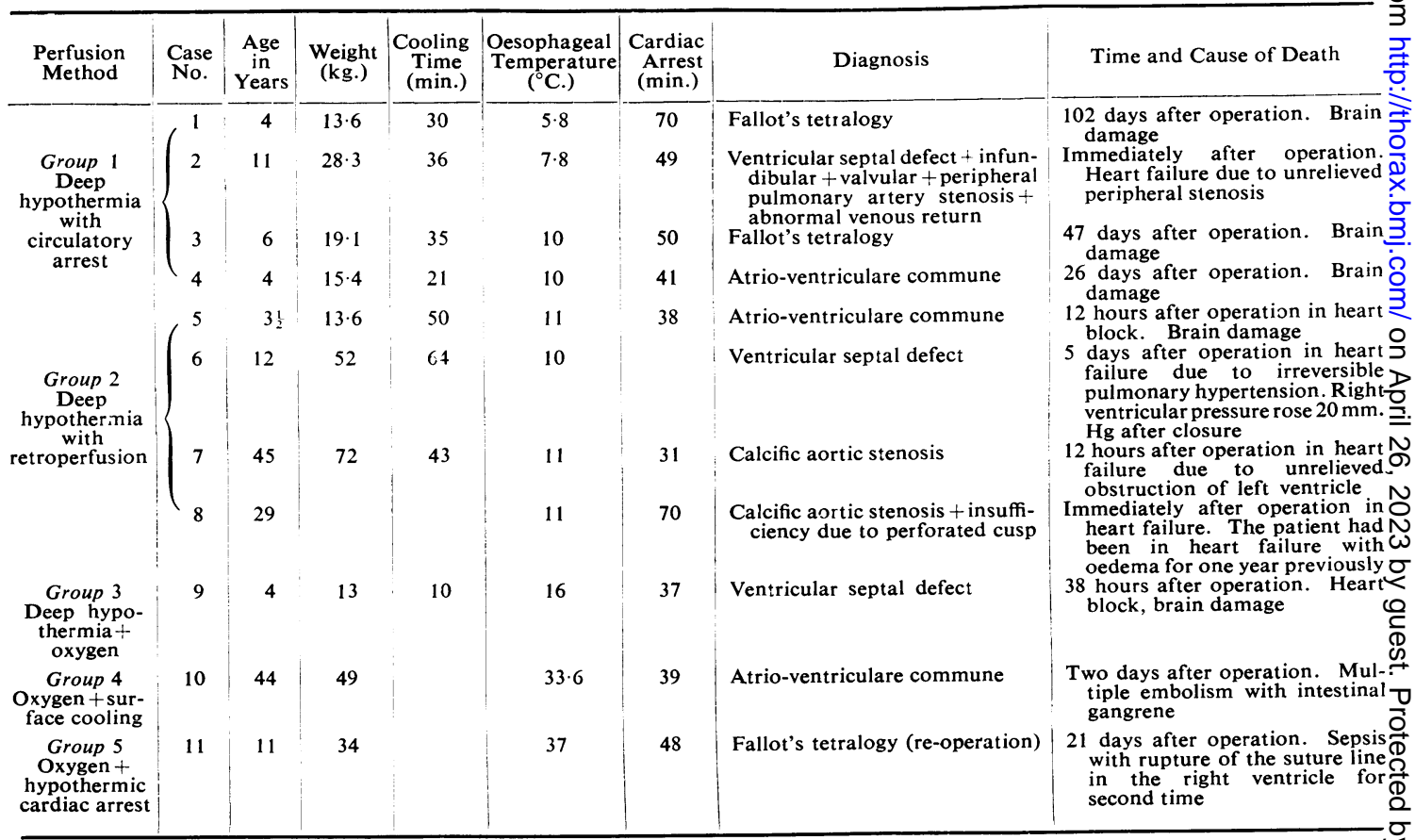


was achieved by reversing events, using both pumps until the heart spontaneously, or by shock, was defibrillated, and finally continued with the pump draining the left atrium until a normal temperature had been reached. There were four deaths (Cases 1, 2, 3, and 4) and six survivors in this group.

Group 2.-The cooling and rewarming were the same as in Group 1, i.e., by extracorporeal cooling without the aid of an oxygenator. During the operation blood from the right atrium to the femoral artery was slowly perfused, and served three purposes. First it kept the temperature at the initial low value of $10^{\circ} \mathrm{C}$., secondly it provided a slow perfusion, (usually $200 \mathrm{ml} . / \mathrm{min}$., so stirring up the blood and preventing thrombus formation), and thirdly delivering oxygen from the saturated blood to the tissues. After 30 minutes of retroperfusion the oxygen content of the perfused blood had fallen from arterial to venous level.

Furthermore the blood in the extracorporeal circuit was diluted with $300-500 \mathrm{ml}$. low molecular dextran (Pharmacia) in order to bring the haematocrit below $35 \%$ and diminish viscosity and danger of aggregation of the corpuscular elements of the blood. There were four deaths (Cases 5, 6, 7, and 8) and three survivors in this group.

Group 3: Deep Hypothermia Combined with Pump OXYGENATOR.-Using the spinning disc oxygenator the temperature was brought down to $12-16^{\circ} \mathrm{C}$. when the heart was excluded from the circulation. With the oxygenator in the system the rewarming could start immediately and the temperature could be kept at $25-30^{\circ} \mathrm{C}$. during cardiac arrest. A 4-year-old boy died (Case 9) ; another, a 20-year-old woman, survived one and a half hours of cardiac arrest while an aortic insufficiency was corrected.

Group 4.-The pump oxygenator was combined with surface cooling in one patient (Case 10), first used at $30^{\circ}$ C. to correct an atrial septal defect of the secondary type. A variety of atrioventriculare commune was found and the pump oxygenator was connected.

Group 5.-The pump oxygenator was used at a normal temperature with a small side branch through the heat exchanger for coronary perfusion of cold blood. After hypothermic arrest of the heart the coronary perfusion was discontinued (Case 11).

\section{Methods}

The brains were usually investigated after fixation in formalin, and different parts were examined after staining with Nissl, haematoxylin according to Heidenhain, Weigert-haematoxylin-van Gieson, and fat staining with scharlach $\mathbf{R}$.

\section{REsults}

The results are summarized in Table II.

Group 1.-Four brains were examined.

Case 1.-The brain weighed 1,220 g. Macroscopically the cortex in the parietal region was somewhat patchy.

The microscopical changes were dominated by diffuse disappearance of ganglion cells in the globus pallidus so that only a few ganglion cells remained with a marked gliosis (Fig. 1c). There were also atrophic ganglion cells and remnants of damaged ganglion cells, especially macrogliosis. Similar changes, but not so pronounced, were encountered in the putamen and a small, older softening was seen in the caudate nucleus. In the parietal cortex there were small foci, partly laminar, and ganglion cells had disappeared, especially in the third nerve cell layer with only slight gliosis. Similar changes were also found in the hippocampus (Fig. 2). No changes were found in the cerebellum.

The kidney and liver did not demonstrate significant changes.

TABLE II

THE BRAIN CHANGES

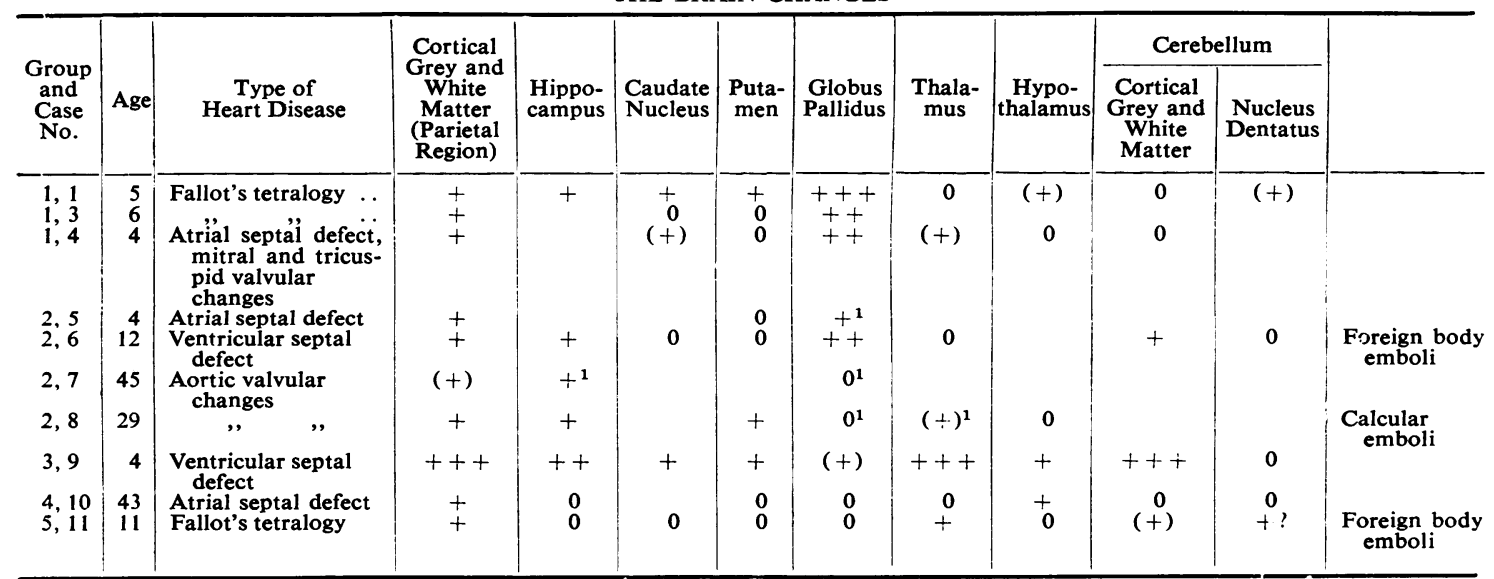


$1 \mathrm{~A}$

1B

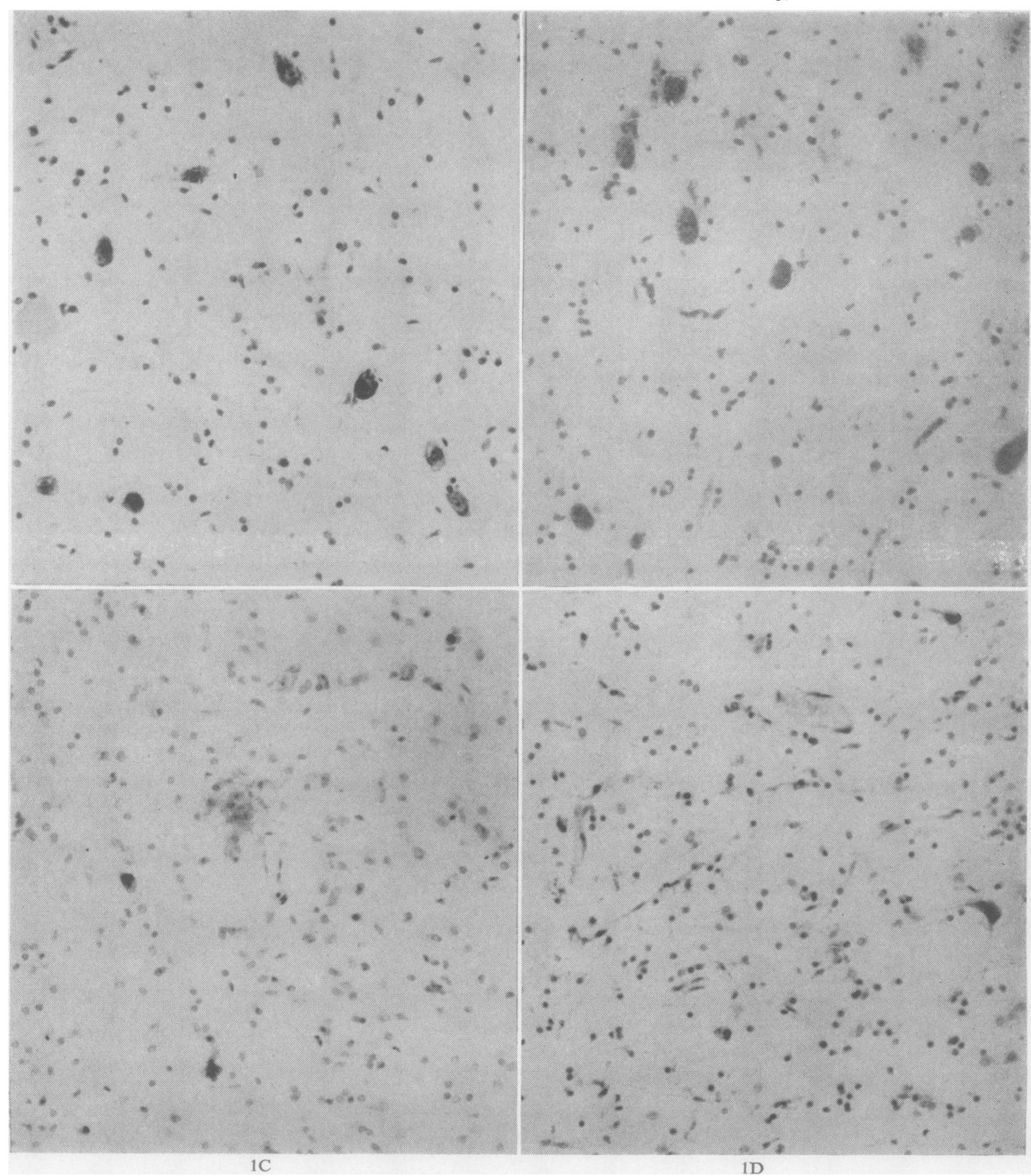

Fig. 1a.-Globus pallidus from a boy aged 8 years who died in aplastic anaemia. No changes are observed. Nissl $\times 180$. FIG. 1b.-Case 11: Globus pallidus without any changes observed. Nissl $\times 180$.

FIG. 1c.-Case 1: Globus pallidus with only a few remaining atrophic ganglion cells and with intense gliosis. Nissl $\times 180$. FIG. 1d.-Case 6: Globus pallidus with disappearance of ganglion cells and slight gliosis. Niss $\times 180$.

Case 2.-The brain was not investigated.

Case 3.-The brain weighed $1,300 \mathrm{~g}$.

Macroscopically it appeared somewhat patchy in the basal ganglia and the parietal cortex was somewhat dark and cyanotic.

The microscopical changes were on the whole similar to those found in Case 1. although the changes in the globus pallidus were not so pronounced.

The kidney and liver did not show significant changes.

Case 4.-The brain weighed $990 \mathrm{~g}$.

Macroscopically the surface was oedematous and somewhat compressed. The cortex was dark and the cut surface of the basal ganglia was patchy. 


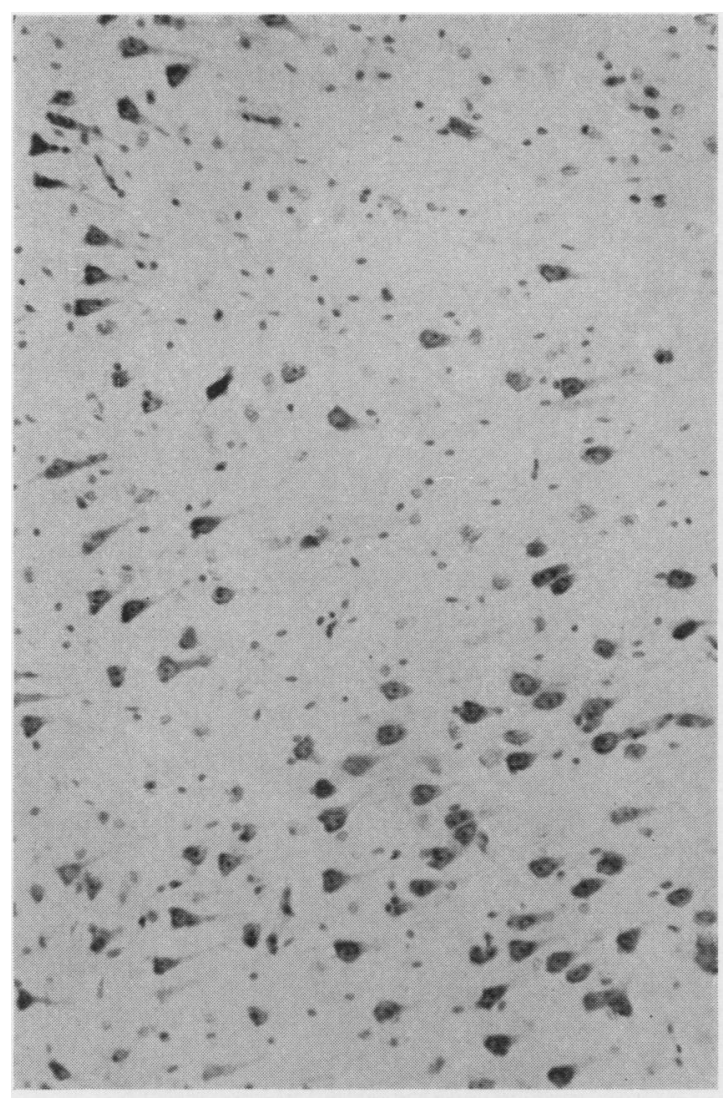

Fig. 2.-Case 1: Focal disappearance of ganglion cells and gliosis in Sommer's sector of the hippocampus. Nissl $\times 140$.

The microscopical changes in the globus pallidus and the parietal cortex were similar to those in Case 1, but less pronounced.

The kidney and liver did not show any significant changes.

\section{Group 2.-Four brains were examined.}

Case 5.-The brain weighed 1,350 g. Macroscopically the surface was compressed.

Microscopically there were found changes in the globus pallidus: very slight acute changes showing a few degenerated ganglion cells and in places somewhat more pronounced older changes with a slightly diminished number of ganglion cells and slight changes in the glia with dominating macrogliosis. In the parietal cortex there were small isolated foci with ischaemic ganglion cell degeneration but no obvious older changes.

There were no changes visible in the kidneys or liver.

Case 6.-The brain weighed 1,550 g., and macroscopically there was slight oedema.
The microscopical changes were most pronounced in the globus pallidus, where the number of ganglion cells was significantly diminished, probably down to half of the normal (Fig. 1d). There was also a certain amount of gliosis. In the parietal cortex ganglion cells in the third layer had disappeared sporadically leaving abundant remnants of degenerated ganglion cells. Myelin sheaths had disappeared, but only insignificant gliosis was seen. Small foci were found where ganglion cells had disappeared and degenerative changes had appeared with some gliosis in Sommer's sector of the hippocampus. In the cerebellar cortex there was a well-localized area where some Purkinje's cells had disappeared with slight gliosis in the molecular layer and perivascular bleeding in the meninges and foreign body emboli in an artery.

In the kidneys there were hyaline cylinders in the tubules and in some places caryolysis with granular cytoplasm but no visible necrosis in the parenchyma. In one liver section a small necrotic focus with infiltration of leucocytes was found, but otherwise no changes were seen.

Case 7.-The brain weighed 1,400 g. Macroscopically there were no visible changes.

Microscopically no acute changes in the ganglion cells were visible in the globus pallidus, but there were some older changes with remnants of degenerated ganglion cells. In the grey matter of the parietal region were found isolated ischaemic degenerated ganglion cells and some very small areas where ganglion cells had disappeared. In one area in Sommer's sector of the hippocampus a rather significant degeneration of ganglion cells without gliosis was found. Furthermore there were smaller older foci where ganglion cells had disappeared and there was gliosis.

In the liver there were slight degenerative changes in the cells centrally in the lobuli with fatty degeneration. In the kidneys there were granular degeneration of cytoplasm and nuclear pyknosis.

Case 8.-The brain weighed $1,450 \mathrm{~g}$. There was slight oedema but no macroscopical changes.

Microscopically in the globus pallidus a few isolated ganglion cells with acute degenerative changes were found and several ganglion cells with calcifications and glios:s. In the putamen and thalamus there were a few foci of ganglion cells with degenerative changes. In the parietal cortex and in Sommer's sector of the hippocampus there were several localized changes with ischaemic ganglion cell degeneration and in a few areas also ganglion cells had disappeared. No gliosis was seen. In one part of the basal ganglia there was a calculus visible in the lumen of a small artery, similar to the calcification found in the aortic valves.

Similar emboli were found in some small arteries of the kidneys and heart. Slight fatty degeneration was found in the liver lobuli.

Group 3.- One brain was examined.

Case 9.- The brain showed several small grey-red foci with diffuse borders. The foci were localized to 


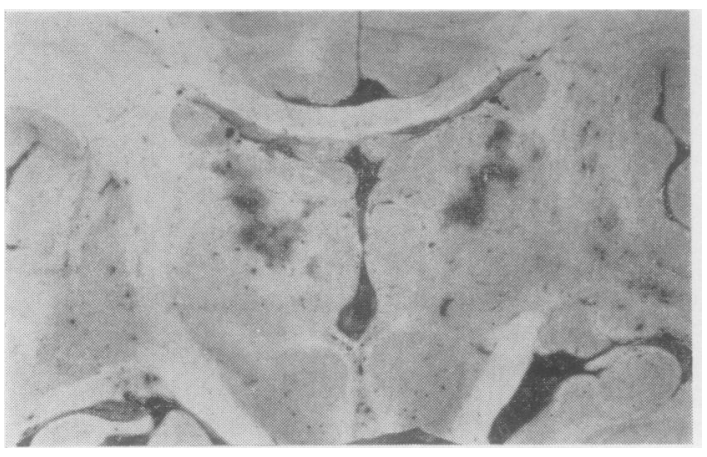

FIG. 3

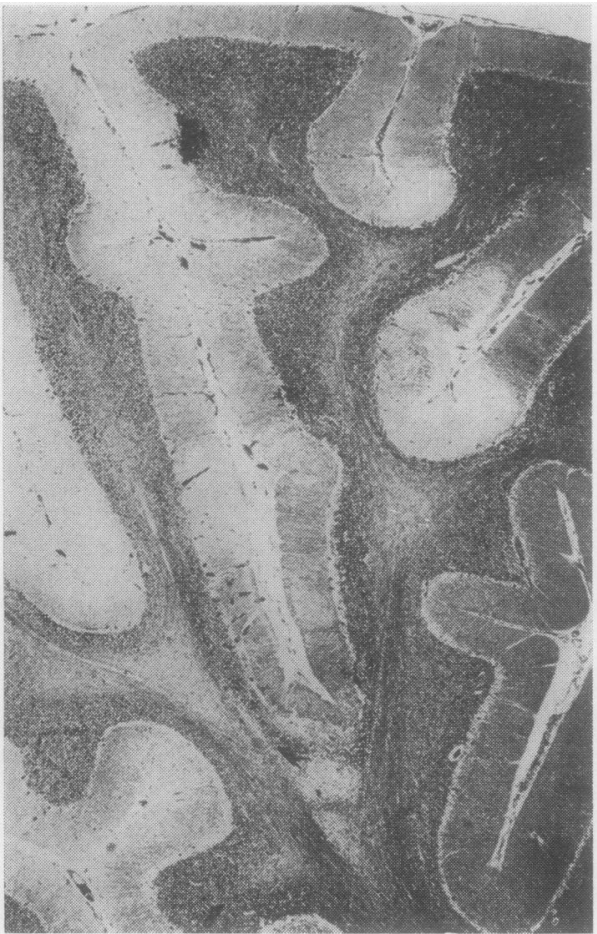

Fig. 5

Fig. 3.-Case 9: Symmetrical necroses in the thalamus.

FIG. 4.-Case 9: Cerebellum with scattered foci of demyelination. Heidenhain-iron-haematoxylin $\times 15$.

FIG. 5.-Case 9: Partly laminar necroses in the cortical grey matter in the bottom of a sulcus and disappearance of myelin sheaths in adjacent white matter. Heidenhain-iron-haematoxylin $\times 15$.

Fig. 6.-Case 9: Thrombus-like aggregates of thrombocytes and some leucocytes in a brain vessel. Weigert : haematoxylinv. Gieson $\times 620$.

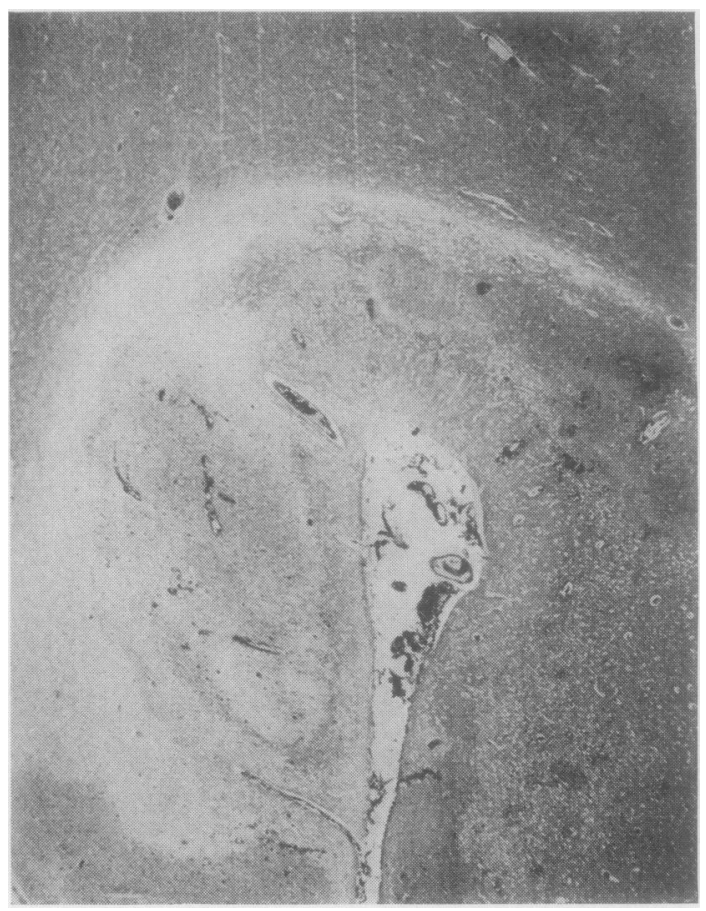

Fig. 4

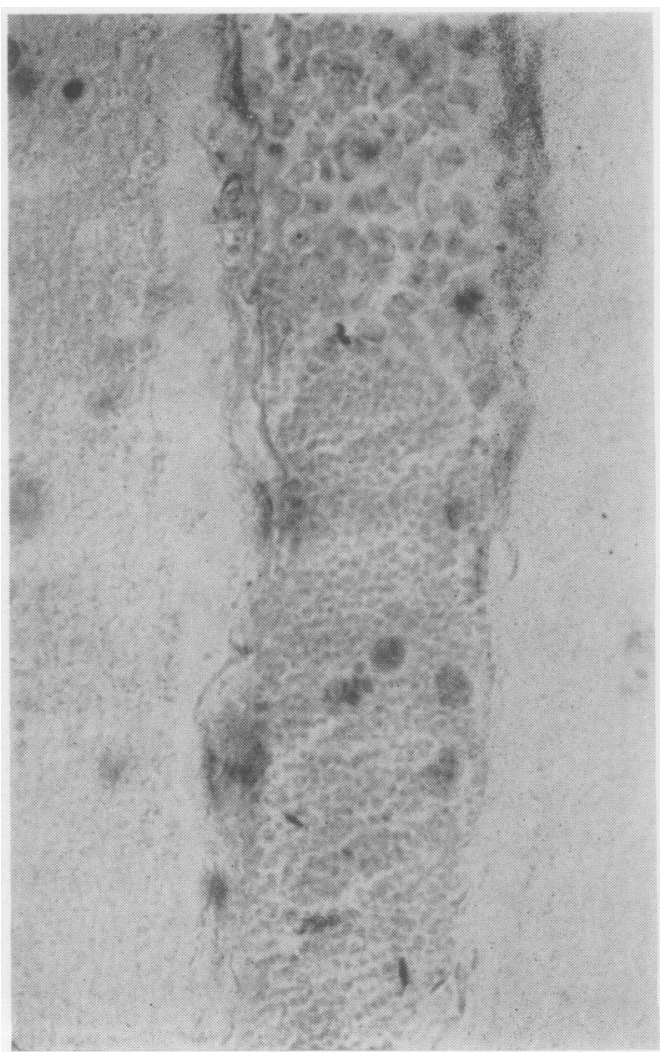

Fig. 6 
the cortical and subcortical areas, often in the bottom of a sulcus, especially in the parietal region bilaterally, but they were also found in the occipital region, especially in the right, symmetrically in the thalamus (Fig. 3), and in both lobes of the cerebellum.

Microscopically the changes were similar to ischaemic ganglion cell change. Ganglion cells had disappeared in the cortex, often laminar in the third and fifth layers, and myelin sheaths had also disappeared in the white matter and there was a homogenizing disorder of Purkinje's cells. There were also regressive changes in glial cells in some places, but no gliosis was visible. These changes were found particularly in the cortical grey and white matter of the cerebrum, in the hippocampus, thalamus, and in the cerebellum, but to a lesser degree in the insula, caudate nucleus, putamen, hypothalamus, and in the nucleus dentatus but also in the globus pallidus, where the changes were insignificant, being confined to a few ganglion cells.

Several sections were investigated for embolic material, but only in a few parts of the parietal region and in the putamen were small, thrombus-like aggregations of thrombocytes and leucocytes demonstrated in a few small arterial branches (Fig. 6).

The kidney and liver showed degenerative changes with hyaline and granular cylinders in the renal tubules and caryolysis in the tubular epithelium and central necrosis in the liver lobuli.

\section{Group 4}

Case 10.-The brain weighed $1,270 \mathrm{~g}$. and there were no macroscopical changes.

Microscopically in the parietal region there were small focal changes in different layers, especially in the third and fifth, with necrosis and disappearance of ganglion and glial cells without obvious gliosis. In the globus pallidus there were no visible acute changes.

Tubular necrosis and several granular cylinders with red blood cells and desquamated tubular cells were found in the kidneys. In the submucous layer of the small intestine there were some small arteries filled with thrombo-embolic material with necrosis of the intestinal wall.

GROUP 5.-One brain was examined.

Case 11.-The brain weighed $1,480 \mathrm{~g}$.

Bilaterally there were some small grey areas without sharp borders in the cortex, often in the bottom of a sulcus and especially in the parietal region.

Microscopically these areas corresponded to complete disappearance of ganglion cells with gliosis as well as increased vascularization with fat phagocytes. These foci were extended over the whole cortical grey matter with some laminar processes in the fifth and sixth cell layers. Also in the thalamus there were sharply demarcated foci but not in the other basal ganglia. In the globus pallidus no significant ganglion cell changes were seen (Fig. 2b). In the cerebellar molecular layer gliosis was found

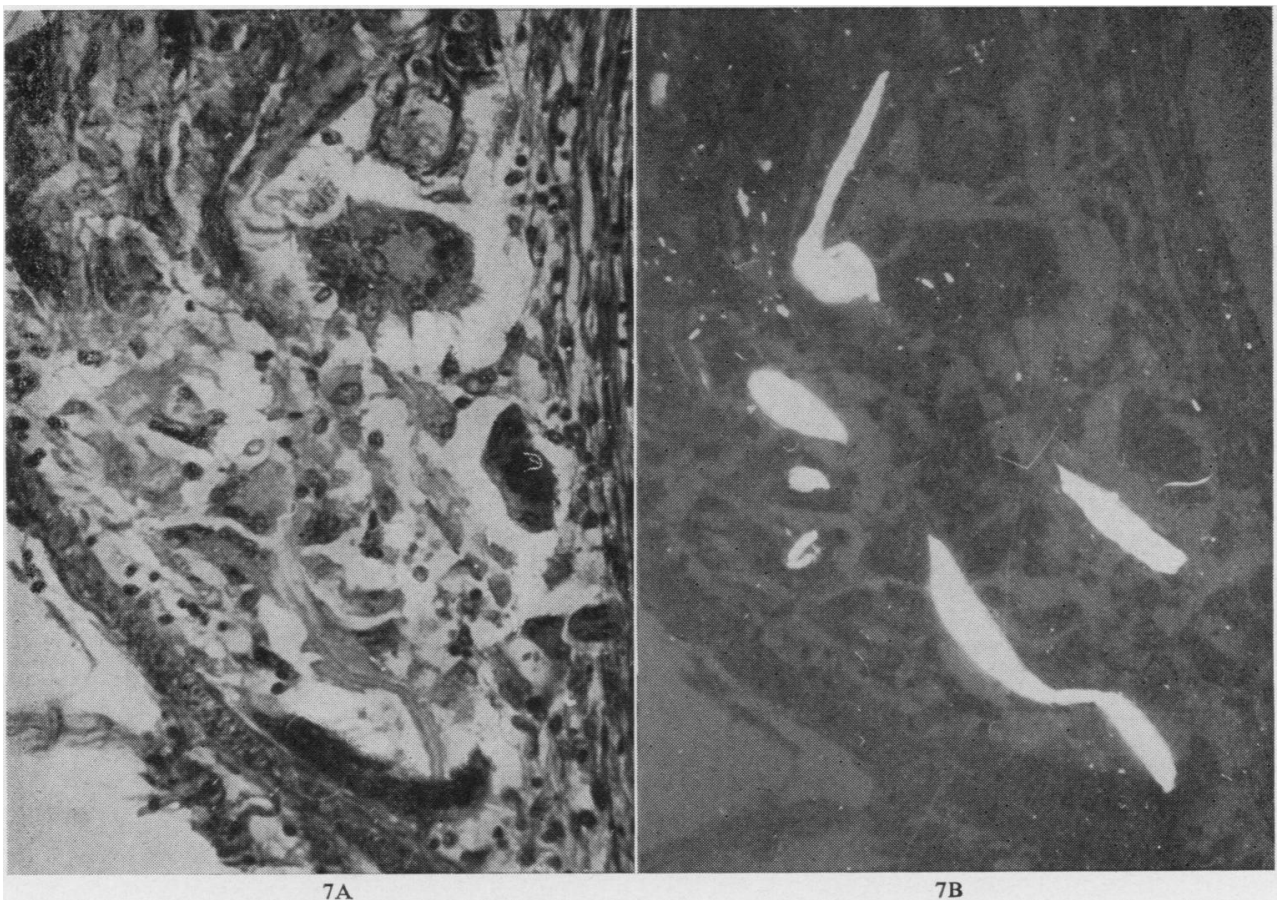

Fig. 7a.-Case 11: Small brain artery containing foreign body granuloma with double refracting threads. Weigert haematoxylinv. Gieson $\times 220$.

FIG. $7 b$.-Photomicrograph of the same intravascular granuloma as in Fig. $7 a$ in partly polarized light. 
in a few places, and, corresponding to them in the parietal region, small foreign body granulomas were found in the lumina of small arteries (Fig. 7).

In the kidneys there were no significant changes, but in the liver slight stasis with central atrophy of the liver cells was observed.

\section{Discussion}

The brain changes vary in the five groups. In the first the changes in all three cases are the same and localized predominantly to the globus pallidus, while the changes in the cerebral cortex are less pronounced. The clinical symptoms were of the same type in these cases, but the time between operation and death varied between one and three months. It is probable that the cause for these changes in the three cases in Group 1 is the same.

In Group 2 the changes vary. Case 6 shows changes similar to those in Group 1 with dominating changes in the globus pallidus that can be ascribed to the post-operative period. There were also changes which may have preceded the operation. The two other cases, Nos. 7 and 8, did not have acute changes in the globus pallidus but showed older changes. In Case 8 the changes might have been due to embolic material. The observation time between operation and death in this group was short (only five days in Case 6 and a few hours in Case 8), which makes it difficult to draw conclusions regarding the pathological findings, especially as a complex picture was found with a mixture of old and acute changes in the globus pallidus. The two children had more pronounced changes than those found in the two adults.

The case in Group 3 demonstrated the most pronounced brain changes in the series and showed a different lesion; the cortex and the thalamus dominated the picture and the globus pallidus was insignificantly affected. The changes in the brains of Groups 1 and 3 may be of different origin.

Groups 4 and 5 show more disseminated foci and in both emboli were demonstrated. The changes encountered in these cases may be caused by emboli. Cases 6 and 8 of Group 2, Case 11 of Group 5, and possibly also Case 9 in Group 3 may also be partly ascribed to emboli. No signs of fat or air embolism have been found during the histological investigation of this material.

It has been stressed that some of these changes date from an occasion before the operation. This is most clearly demonstrated in Cases 5,7 , and 8 . In the cases where it has not been possible to date the different changes, some of the lesions in the brain may have been present before operation. In Group 1, on the other hand, where pronounced clinical symptoms due to the brain changes were encountered after the operation, the eventual presence of some earlier brain changes cannot be important.

The diffuse changes in the brain may be divided into two groups according to the principal localization of the process. One showed changes localized to the cerebral cortex, especially to the region of the arteria cerebri media, the hippocampus, cerebellum, and thalamus, while the globus pallidus was not significantly changed. In the other the changes were predominantly in the globus pallidus, but these cases also showed minor changes in other parts of the brain.

These two types of diffuse change in the brain are generally considered characteristic of two different kinds of pathological course, i.e., the dominating changes in the globus pallidus are usually ascribed to hypoxaemic hypoxia; they are found in carbon monoxide poisoning. The changes in the cortex are usually ascribed to diminished blood flow to the brain. No definite conclusions can be drawn regarding those two types, although some paralysis of the enzymatic system in deep hypothermia causing these changes in the globus pallidus may be discussed. The other possibility is intravascular aggregation of red blood corpuscles, or, more probably, of the thrombocytes and leucocytes.

As focal necrosis scattered over the brain is found, the explanation may be a sequestration of the thrombocytes and white blood corpuscles forming thrombi in the brain capillaries during cooling. Such an aggregation of thrombocytes and white blood corpuscles was demonstrated in some vessels in the brain of Case 9 (Fig. 6). The thrombi may come early during cooling and block the vessels to one area so that its temperature and oxygen demand do not fall equally quickly, causing local anoxic damage. Another possibility is that the sequestration of thrombocytes and white blood corpuscles cause thrombi in certain areas in brain during the lowest temperature. During rewarming the number of thrombocytes and white blood corpuscles after a low concentration usually return to a normal one. In the two surviving children a diminution from 189,000 to 88,000 returned to 190,000 in one case, and a drop from 230,000 to 63,000 returned to 187,000 thrombocytes during the rewarming in the other. If sequestrated thrombocytes and white blood corpuscles return to the circulating blood too slowly from the brain during the rewarming, obstruction to the circulation with foci of anoxic necrosis will occur as in Case 9.

In three of the six children who died, the thrombocytes never did return to normal values 
during or after the rewarming. In Case 9 (compare Fig. 6) a drop from 286,000 to 57,000 thrombocytes during cooling was found and even four hours after rewarming only 52,000 thrombocytes were counted. In Case 5 there was a drop from 180,000 to 24,000 thrombocytes and after the rewarming only 20,000 were counted.

A high concentration of heparin, $5 \mathrm{mg}$. per $\mathrm{kg}$. body weight, and an admixture of $500 \mathrm{ml}$. low molecular dextran for the dilution of blood, has not prevented the sequestration of thrombocytes and white blood corpuscles. The donor blood was tested for cold agglutination and all positive bottles were excluded. The speed of cooling does not seem to influence the result, as exactly the same cooling and rewarming time was used in the two surviving children as in the others. Furthermore, the flow was calculated according to body weight.

It does not seem to us that this investigation has proved that the cause of the scattered changes in the brain in all cases is sequestrated thrombocytes occluding certain vascular areas in the brain, thus mechanically explaining the scattered foci. Scattered foci in the brain are characteristically also found after more general insufficiency of the cerebral circulation. According to Scholz et al. there are reasons to believe that a circulatory insufficiency in one area does not only change the brain parenchyma but also the vessels. Hypoxia in the vessels may lead to functional changes, i.e., vasodilatation and stasis in the damaged areas.

The cause of the second type of brain changes with dominating changes in the globus pallidus (found in Group 1 and in Cases 5 and 6 of Group 2) could possibly be the sequestrated thrombocytes. This type of brain change has been described in connexion with hypoxaemic hypoxia.

The brain damage was the cause of death in five children below 6 years of age, but could not be considered responsible for the fatal outcome in any adult patient. Only two children, 9 and 10 years old respectively, survived deep hypothermia, while nine adult patients survived the procedure without neurological symptoms. One patient, aged 19, had after operation experienced convulsions of epileptic type once every month. The relatively higher oxygen consumption in children compared with that in adults was first considered.

In Group 1, a circulatory arrest of 47 minutes was tolerated by a 32-year-old woman but only of 38 minutes by a 9-year-old child. A circulatory arrest of 70,50 , and 41 minutes respectively caused brain damage in children. Other anoxic brain complications were not severe immediately after operation. In our cases a few symptoms were observed during the first few days, but then extrapyramidal symptoms slowly progressed, the children stopped talking and could not walk, had contracted crossed legs and contracted arms and hands. The symptoms progressed slowly, with difficulty in swallowing and, later, death.

Cerebral damage due to anoxia could be excluded in one patient (Case 5) in Group 2 where a recirculation of $200 \mathrm{ml} / / \mathrm{min}$. from the right atrium to the femoral artery resulted in a systemic blood pressure of $50 \mathrm{~mm}$. $\mathrm{Hg}$ during cardiac arrest for 38 minutes at $11^{\circ} \mathrm{C}$. in a $3 \frac{1}{2}$-year-old child. The cause must be ascribed to the deep hypothermia (probably due to thrombocyte aggregation) when the incorporation of the spinning disc oxygenator in the circuit did not prevent brain damage in a 4-year-old child (Case 9) operated on at $16^{\circ} \mathrm{C}$.

The fact that only children and no adult patients have suffered this complication cannot be explained. Some evidence points to a difference between the brains of adults and of children under 2-3 years of age regarding the blood-brain barrier. In experiments on cats and dogs Lourie et al. observed a partial disruption of the barrier to trypan blue only at brain temperatures at and below $9^{\circ} \mathrm{C}$.

In dogs Connoly, Harris, Bruns, Smith, Guernsey, and Boyd (1960) found that by selective brain cooling to $20^{\circ} \mathrm{C}$. the Purkinje cells were diminished in number regardless of whether any vascular occlusion was performed.

\section{SUMMARY}

The use of deep hypothermia by extracorporeal cooling must be re-evaluated. Severe brain damage has been encountered in children operated on both with and without an oxygenator. For the present deep hypothermia is recommended, in combination with the spinning disc oxygenator, only in adults who have aortic valvular disease or aneurysm in the arch of the aorta.

\section{REFERENCES}

Connoly, Harris, Biuns, Smith, Guernsey, and Bond (1960). Surgical Forum, 11, 405.

Drew, C. E., and Anderson. I. M. (1959). Lancet, 1, 749.

and Benazon, D. B. (1959). Ibid., 1, 748.

Gollan, F. (1959). Physiology of Cardiac Surgery. Thomas, Springfield, Illinois.

Kalz, F., Friedman, H., Schenker, A., and Fischer, I. (1946). Arch. Neurol. (Chicago), 56, 55.

Lourie, H., Weinstein, W. J., and O'Leary, J. L. (1960). J. nerv. ment. Dis., 130, 1 .

Scholz, W. (1957). In Handbuch der speziellen pathologischen Anatomie und Histologie, ed. O. Lubarsch, F. Henke, and R. Rössle, band 13, teil 1, bandteil B. Springer, Berlin.

Villalobos, T. J., Adelson, E., Riley, P. A., Jr., and Crosby, W. H. (1958).J. clin. Invest., 37,1

Wensel, R. H., and Bigelow, W. G. (1959). Surgery, 45, 223. 